\section{The Technology Scenarios Programme at Risø National Laboratory (DK)}

\author{
by Per Dannemand Andersen and Birgitte \\ Rasmussen, Risø National Laboratory
}

The research programme Technology Sœnarios is part of the Systems Analysis Department at Risø National Laboratory. The aim of the programme is to develop methods for analysing commercial, societal and scientific possibilities and consequences in relation to the selection, development and commercial application of new technologies. Risø is a national laboratory under the Danish Ministry of Research and Information Technology. The Systems Analysis Department at Risø undertakes research within systems and technology analysis in the areas of energy technology, industrial technology, bioproduction and radiation safety.

\section{Organisation}

Ris $\varnothing$ National Laboratory was founded in 1958 as a nuclear research facility of the Danish Atomic Energy Commission. It carries out research in science and technology, providing new opportunities for technological development for Danish society. It contributes to the development of environmentally acceptable methods for agricultural and industrial production as well as for the generation of the energy necessary for modern society. Ris $\varnothing$ has more than 900 employees, including more than 350 academics (specialists, scientists, post doctoral, $\mathrm{PhD}$ etc.). The research activities are carried out within the following areas: Wind energy; Systems and technology analysis; Energy materials; Polymers; Optics and sensors; Plant biotechnology; Radiation safety. Ris $\varnothing$ collaborates at Danish, European and international levels with universities, research institutions, technological institutes and private companies.

The research in systems and technology analysis develops and applies methods for the technical, economic and environmental analysis of complex technological systems as energy systems and industrial systems. By the middle of 2001 the total number of employees in the department was 65 . This included an academic staff of 60, namely engineers, natural scientists, economists, psychologists and social scientists.

The research activities of the Systems Analysis Department are undertaken within the following research programmes:

- Energy Systems Analysis: develops methods for analysing energy, environmental and economic issues, and the interaction between them, as well as new energy technologies and their adaptation to complex energy systems.

- Energy, Environment and Development Planning (UNEP Centre): develops methods for analysing global, regional and mtional energy and environment issues and supports the development of national planning capacity.

- Safety, Reliability and Human Factors: develops methods for analysing the safety and reliability of complex technical systems, taking into consideration the strong coupling of technical, organisational and human aspects.

- Technology Scenarios: develops methods for analysing commercial, societal and scientific possibilities and consequences in relation to the selection, development and commercial application of new technologies.

\section{Technology Scenarios Programme}

The Technology Scenarios Programme was established in 1998. The programme is staffed with technical and natural scientists as well as scientists from the fields of economics and business administration reflecting the cross disciplinary working field of the programme. In 2001 the group has 8 academic staff me mbers.

The research is focused on the development of theories and research methodologies for technology analysis based on case studies and empirical problems at the meso-level (the organisational level of the industrial sectors, the firm or the research institution).

\section{Research themes}

The research is centred on two themes, both focusing on the areas of energy technology, industrial technology and bioproduction. 
Theme 1 - Development of operational theories and methodologies for technology foresight studies and other methodologies for prioritising and evaluation of research and application of technology

This research theme is important for several reasons. It is generally acknowledged that the accelerating development of new technologies opens up a range of challenges and opportunities for industrial enterprises, for research $\boldsymbol{\alpha}$ ganisations and for the society as a whole. But it also gives a new dimension of uncertainty in managerial decision processes. Allocation of the R\&D efforts and maintaining the technological edge are strategic key issues for enterprises (and for research organisations and mtions) in order to maintain their competitiveness. Experiences of other countries in technology foresight and research prioritisation can improve Danish approaches and methodologies. But, international experiences cannot be directly translated to a Danish context. Danish methodologies, taking into account Danish industrial structure and Danish political traditions, need to be developed. It is one of our aims to develop operational methodologies for prioritising the R\&D effort. Our emphasis is put on a meso-level (industries, industry sectors and research organisations). Based on this meso-level platform of competence, it is also our aim to contribute to and participate in similar activities on the macro level (national Danish level and international level).

Theme 2 - Development of operational theories and methodologies for prospective analysis of impact, robustness and consequences of research and new technologies integrating different approaches (e.g. technology foresight, risk assessment and life cycle analysis)

This research theme is of interest because the increasingly faster technological development may significantly change the physical and economical environment of a product during its lifetime. Planning a nation's electricity supply or a power company's generation capacity portfolio must take into account technologies available 10 or 20 years ahead. Until very recently there have only been conceptual proposals to explore the integration of LCA with other types of technology analyses, e.g. technology foresight studies. The typical life cycle inventory focuses on energy, material and environmental releases. Other aspects could be of interest in technology foresight studies, e.g. public perception, ethical aspects, and economic aspects. There is a need to investigate how new aspects can be integrated in the life cycle $\dot{n}$ ventory and to identify the aspects of importance for a technology foresight study

\section{Projects and experiences - Theme 1}

\section{Sensor Technology Foresight}

Sensors and transducers are the front-end technology for instrumentation and measurement purposes. Sensor technology is one of the technologies that is expected to play a major role in the future, and in a knowledge based economy only firms that are very innovative, grow fast and create most value will do best in tomorrow's competition. The first part of the study focused on technology mapping to identify the boundaries and categories of the technological domain (desk research, state-of-the-art and case studies). Second, a technology scanning process sought out major distinguishing features in the technological domain in a timeframe of 2000-2015 (literature scanning and expert workshops). The last part was a Delphi questionnaire to evaluate the validity and reliability of statements about sensor technology development. The project is financed by the Sensor Technology Center A/S.

\section{REMAP}

The full title of the project is R\&D Management Processes under Rapid Change. Management of research and development is based on decisions taken at a high level of uncertainty and involves a number of different actors and different perspectives (e.g. the political system, researchers, managers, research institutions, firms, etc.). Thus, a dynamic and interdisciplinary understanding is needed for the management of these complex processes. It is the aim of REMAP to provide such an understanding from its unique combination of research partners (i.e. technical, economic and social scientists, industry representatives) through the development of an integrated model for under- 
standing, managing, prioritising and evaluating complex research processes in both public and private R\&D. Our activities in REMAP include the two $\mathrm{PhD}$ projects "Strategic management of the venture capital activity" and "Decisionmaking and strategic thought in turbulent environments (with nano technology as case)". Further, a PhD course on management of esearch and innovation has been developed and organised by the REMAP group. The project is financed by the Danish Research Agency. Further information at: www.remap.dk.

\section{Experience curve - A tool for energy policy programmes assessment (EXTOOL)}

The development of experience curve methodologies for the assessment of energy policy programmes is of interest to all EU countries and the European industry. In this project, the experience curve methodology is based on case studies of wind power and analyses of cost reduction due to different wind policy programmes including:

a) the development of experience curves;

b) the development of a database and a software of experience curves;

c) analyses of different sources of cost reduction, and

d) analyses of the effect of different energy policy programmes in relation to experience curves (e.g. the effect on the experience curve itself, and the cost effectiveness of different programmes measured by the experience curve).

The project is sponsored by the European Commission.

\section{DECENT}

The DECENT project is addressing decentralised generation technologies and their potentials, success factors and impacts in the liberalised EU energy market. An important part of the project is related to the identification of success factors and impeding factors for decentralised generation and the assessment of the impacts of an increased utilisation of these technologies on the energy sector in the single market, including the evaluation of energy savings, emission reductions and social objec- tives. In addition it will be analysed at which costs the stated benefits of the decentralised generation projects are achieved. A number of case studies for different decentralised technologies will be carried out in the project, to systematically identify success factors and impeding factors for the development of decentralised generation. A Delphi methodology, including questionnaires and expert panels, will be applied to identify expected or likely future developments in decentralised generation technologies. The project is sponsored by the European Commission.

\section{New strategy at Risø}

Ris $\emptyset$ 's current strategy expires at the end of 2001, and a new strategy has been developed during 2000. The process included two parallel tracks; a decision part (where actions were taken by managerial layers at Ris $\varnothing$ ) and an analysis and advisory part (where facts and points of views were processed as input to the decision process). Five themes for advisory panels were determined by Risø's Management. The Technology Scenarios Programme supported Risø's management especially during the advisory part of the strategy process, which comprised five elements:

1) Mapping of Risø's competencies and related areas of technology;

2) Scanning technological and scientific trends for the five themes;

3) Principles for nomination of panel members for each of the five themes (external experts and internal senior staff);

4) Facilitation of panel meetings;

5) Reporting.

\section{Prospects for a Nordic Technology Foresight}

Technology foresight is increasingly used by governments, funding agencies, R\&D institutions and private companies as a tool for prioritisation of $R \& D$ funds and learning. In the Nordic countries attempts are made to embark on foresight activities, but without a common knowledge pool nor co-ordination and hence no Nordic synergies. The pilot project seeks to map the state-of-the-art of Nordic technology 
foresight activities, to identify partners with a common interest in co-ordinating technology foresight activities, and to formulate a concrete technology foresight project. In particular, the pilot project seeks to identify Nordic partners with interest in technology foresight, to build commitment and to make a concrete Nordic technology foresight project proposal. The project receives funding from the Nordic Industrial Fund.

\section{Projects and experiences - Theme 2}

Identifying the drivers for a genetically modified crop using life-cycle methodology in a technology foresight framework

This case study focused on the development of a genetic ally modified ryegrass, which is incapable of producing stems and flowers (biological encapsulation). The method used combined a technology foresight framework using life cycle inventory to define the problem complex and a stakeholder panel to identify drivers (of change) that influence the direction of future development, and weighted stakeholder questionnaires to prioritise these drivers. Once quantified, the weighted stakeholder opinion generated a clear criterion for prioritising drivers that were judged to be important in the future development of a genetic ally modified ryegrass but whose precise impact was uncertain. The project is financed by the Danish Research Agency and carried out under the auspices of the "Centre for Bioethics and Risk Assessment" in Denmark.

\section{Risk assessment of genetically modified crops}

In Denmark the National Forest and Nature Agency is responsible for approval of genetically modified crops. A part of the approval procedures is the preparation of an environmental risk assessment generally comprising ecological and agricultural effects together with human health issues. A project has been initiated with the purpose to develop a framework for the planning, preparation and application of risk assessment based on the experiences already gained from the field of risk assessment of gnetically modified crops supplemented by experiences from other disciplines with a longer tradition for application of risk and technology assessment methodologies, e.g. chemical process industry.

\section{Environmentally sound development of wind turbines}

Wind energy is a central part of the Danish energy policy with the goal of reaching $50 \%$ wind power in the Danish electricity supply by the year 2030. Wind power will compete with conventional energy technologies emphasising the need of a tool for long-term comparison of technologies. This project has three aims. The first aim is to analyse the environmental effects of wind turbines during production and decommissioning of wind turbines in a long-term view, i.e. 2020 to 2030 for manufacturing and 2040 to 2050 for dismantling. The second aim is to set up societal recommendations concerning decommissioning, recycling and handling of waste for existing and future wind turbine concepts and components. Finally, it is the aim to contribute to the development of a methodology for using LCA as a tool for designation of experts and for opening up perspectives in the long-term. The project is financed by the Danish Energy Agency.

\section{Contact}

Per Dannemand Andersen Technology Scenarios Programme Systems Analysis Department

Ris $\emptyset$ National Laboratory

DK-4000 Roskilde, Denmark

Tel.: +45 46775108

Fax: +45 46775199

E-Mail: per.dannemand@ risoe.dk

URL: http://www.risoe.dk/sys/tes/

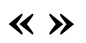

